\title{
Identifying credit constraints using direct elicitation methodology: the case of Indonesia
}

\author{
Sigit S. Wibowo \\ Department of Management, \\ Faculty of Economics and Business, \\ Universitas Indonesia, \\ Depok, 16424, Indonesia \\ Email: sigit.sw@ui.ac.id
}

\begin{abstract}
This study considers how credit constraints come to exist and how to identify them. Credit constraints may arise from market mechanisms: the demand for loans and the supply of loans. In order to assess credit constraints, I use direct elicitation methodology and then examine the gathered information and other household characteristics by applying a multinomial logit model. Using an access-to-finance survey conducted by the World Bank, I find that Indonesian households are likely to experience supply-side constraints rather than demand-side constraints. I also find that financial literacy plays a vital role in accessing services from formal financial institutions. I estimate welfare loss by elaborating several types of constraints: households constrained because of risk-related reasons experience a loss in annual income of between Rp 16 million and Rp 19 million.
\end{abstract}

Keywords: access to finance; A2F; credit constraints; direct elicitation methodology; DEM; Indonesia.

Reference to this paper should be made as follows: Wibowo, S.S. (2018) 'Identifying credit constraints using direct elicitation methodology: the case of Indonesia', Int. J. Governance and Financial Intermediation, Vol. 1, No. 1, pp.59-81.

Biographical notes: Sigit S. Wibowo received his $\mathrm{PhD}$ in Economics at Durham University Business School. He is a Lecturer at the Department of Management, Faculty of Economics and Business, Universitas Indonesia. His research interests are related to financial economics, risk sharing and risk management.

This paper is a revised version of a paper titled 'Identifying credit constraints using direct elicitation methodology: the case of Indonesia' presented at the 2014 Asian FA Annual Conference, Bali, Indonesia, 25 June 2014.

\section{Introduction}

Credit or loans are essential for household economies in various ways. Households use them whenever consumption smoothing is needed to cope with income changes or health 
shocks. They can also support home business and investment, particularly for financing working capital. Credit can be very flexible for households if they hold credit cards which serve as a tool for household money management or for revolving credit lines. This means credit is available up to certain levels for households who have this kind of facility. However, many households may find it extremely difficult to gain credit access. In these cases, the difficulty in accessing credit or financial markets may impede household welfare.

From a macroeconomic perspective, credit or financial markets are important to an economy: they affect economic growth and equality as well as investment and technology choices. Well-developed credit markets are crucial for conducting financial transactions through different credit channels. However, credit markets are not properly established in developing countries (see for example Deaton, 1992).

A study by the World Bank (2009) shows that only 50\% of Indonesia's population have adequate access to financial services. The rest is considered as un-bankable with the majority living in rural areas and working in the informal sector. This study shows how banks and other financial services are heavily concentrated in urban area, particularly in Jakarta which is regarded as 'over-serviced'. In rural areas, the granularity of customers matters. Four financial institutions providing financial access in rural area are: government-owned commercial bank (BRI or Bank Rakyat Indonesia), government-owned pawnshop (Perum Pegadaian), people credit banks (BPR or bank perkreditan rakyat), and various types of formal and informal microfinance institutions. These institutions serve different segments and have different regulations. The first three are formal financial institutions, which have formal regulations of their operational system. The latter is dominant compared to others in terms of the number of people participating in different ways.

Furthermore, Ghosh et al. (2001) describe important features that characterised informal credit and financial institutions in developing countries. The features are:

1 contracts are unlikely to be written in advance when credit agreements emerge

2 highly segmented credit markets with repetitive lending and long-term relationships

3 higher interest rates compared to average interest rates in formal institutions

4 closely related with other markets for example labour, agricultural, and land markets

5 a large amount of credit rationing or the inability to borrow according to household needs.

Credit constraints can be defined as the inability of some households to borrow against their future income, which is possibly due to lenders' perception toward this inability (for more explanation, see Deaton, 1991). The main question here is how to identify and measure accessibility of credit markets for households. Most research usually uses one of two approaches in estimating credit constraints based on participation in credit markets: 'indirect' and 'direct' methods. The 'indirect' method tries to assess conditions when the credit supply cannot match the demand for credit. This method has many difficulties in terms of distinguishing supply from demand equations. The other method is based on the survey data on credit information, particularly on credit applications and related conditions that emerge from these processes. Using this method, the researchers directly ask the households about their credit rationing. 
This chapter investigates credit constraints in Indonesian households mainly by identifying and classifying the constraints using direct elicitation methodology (DEM). This is important in order to understand the household problem of accessing formal financial institutions. Furthermore, the welfare loss is estimated for those who have difficulties in accessing credit markets. This study focuses on formal financial institutions since these institutions provide several advantages to households such as low interest rates for loans and consumer protection. The number of formal financial institutions has increased significantly for the past 30 years. However, due to informational disadvantage and transaction costs, the formal financial services are limited to mainly in urban areas. Some households are still reluctant to fully access and use formal financial services. Moreover, they may end up by getting loans from informal financial institutions which are often more expensive than formal financial institutions.

This paper aims to identify credit constraints and its welfare loss to Indonesian households who are constrained. This study finds that the constraints occur mostly due to supply-side constraints. Financial literacy is the key role in identifying those who are not credit constraints. The rest of the chapter is organised as follows. Section 2 describes various methods used in empirical measurements of credit constraints. Section 3 discusses methodology and empirical strategy by utilising Access to Finance (A2F) survey data. Section 4 gives the empirical findings and discussions. Section 5 provides concluding remarks.

\section{Related literature}

An individual or household is said to have access to finance if he or she can use formal or informal financial services in the right form and at reasonable prices whenever he or she needs it. This definition can be considered as full access to finance. One may have partial or limited access due to different dimensions for example the scope of products, institutional, quantity, price, gender and age. Access to finance means an economic opportunity for those who have the access since they are able to take advantage from financial markets to improve their welfare.

Fernando (2007) argues a root cause of the supply side constraints is the conventional view the potential market holds of those on lower incomes. This view focuses on two interrelated ideas with regard to these particular people. The first is the potential profit of the low end of financial markets. The second is the financial services through governmental programmes and social-oriented institutions. In many developing countries, conducting transactions with formal financial institutions is often perceived as a complicated procedure carrying high transaction costs, and may even be intimidating, especially for women and those who have low financial literacy. Binswanger and Sillers (1983) also find that risk aversion may affect different types of small-scale potential creditors: it prevents them applying for a loan especially when collateral is required.

Credit constraints limit household welfare and access to financial services to cope with needs and mitigate risks. Jappelli (1990) defines credit constraints as any situations where economic agents report unsatisfied demands for credit or any other borrowings from financial institutions. In this context, financial institutions refuse to grant credit due to the inherent risky conditions of the agents or asymmetric information about the ability of the agents as lenders. 
However, a household with no or small debt cannot be assumed as likely to be constrained since the level of credit or debt is a function of credit supply and the household's demand for credit (see Grant, 2007). Boucher et al. (2009) classify credit constraints into two types:

1 ex ante

2 ex post credit constraint.

The former exists when households are not able to secure loans and are unable to take desired actions and engage in profit maximising investment. The latter exists when they are prevented from borrowing after decisions are made and investment outcomes are realised. The credit constraints would have implications on the household's ability to pool risks across time. As the facility to absorb random shocks in income and consumption decrease, there would be a change in behaviour towards risk. Eswaran and Kotwal (1990) argue unequal ability to access financial market would have an impact on the degree of risk aversion. In other words, the risk aversion can be a reflection of inability to cope with downside income risks.

Petrick (2005) documented various empirical methods on credit rationing along with specific strengths or weaknesses. He classified various studies on credit rationing into six methods:

1 measurement on loan transaction costs

2 qualitative information from interviews

3 qualitative information from interviews using the credit limit approach

4 spill-over effects with regard to secondary credit sources

5 economic household modelling

6 econometric analysis of dynamic investment decisions.

The first four are seen as direct methods in the sense that the inference is made based on direct information from borrowers. The last two can be classified as indirect methods because they analyse the consequences of credit rationing through econometrics techniques, which seek to identify credit constraints by assessing the conditions between supply and demand of credits or loans. The interaction between these two types may exist since indirect methods use some information generated by direct methods.

Credit constraint identification through measurement of credit transaction costs requires collection of specific information about households, in particular the calculation of the effective costs to gather a relevant price variable. These costs may result in negative investments and therefore lead to exclusion of those who are not able to repay nominal interest rests. Moreover, the value of the price variable is difficult to measure because it requires distinguishing different types of costs that are necessary for credit approval, monitoring, and the costs that are due to shirking loan officers or inefficient practices. Schneider (1987) argues that providing a theoretically accurate measurement of transaction costs is difficult whenever the opportunity costs of related transaction activities are not known.

The second method identifies credit constraints from direct questions about credit application and approval using qualitative information from survey data. For instance, households can be classified into four categories according to demand for credits: 
1 did not have any demand for credits

2 had demand for credit but did not apply

3 applied for credit but was rejected

4 received a credit.

The last category can be divided into two subcategories: received full or partial credit. Therefore, the first and fourth category is not credit constrained, except for those who received partial credits. The second and third category can be considered as 'credit constrained'. The DEM proposed by Boucher et al. (2009) falls under this classification.

This study attempts to contribute by identifying credit constraints and estimating welfare loss for general households with Indonesian households as a case study. Secondly, the contribution of this study also investigates the credit constraints with risk preferences and financial literacy.

\section{Methodology}

A household's decision to borrow depends on the demand for credits and credit supply. Grant (2007) argues that one cannot assume that households with little or no credit are likely to be credit constrained. The observed level of household's credit is a function of household's demand for credit and the credit supply from lenders or financial institutions. Furthermore, there are three aspects that should be addressed regarding the borrowing behaviour of households. The first aspect is the number of households who are credit constrained. The second is how to distinguish households who are likely to be constrained and unconstrained. The third is how much welfare loss its cause by credit constraints.

In observing borrowing behaviour, one must consider asymmetric information that may exist between borrowers and lenders which leads to moral hazard and adverse selection. In the absence of insurance markets, households are called to have notional demand which is defined as a demand for credit in the first-best world when perfect credit markets exist. In the presence of asymmetric information, households' demand for credit can be defined as effective demand.

Following Boucher et al. (2009), the presence of asymmetric information in the credit market may also lead to non-price constraints: quantitative, transaction-cost and risk. Quantitative rationing takes place when a potential borrower has a profitable project or a productive activity but is unable to find a credit supply. This can be considered as supply-side constraints.

The other two rationing categories imply low level of demand for credit compared to quantitative rationing. Transaction-cost rationing occurs when a potential borrower has positive notional demand but does not have effective demand for credits due to transaction costs. Risk rationing occurs when a potential borrower has a profitable project or productive activity but chooses to withdraw due to lower return. The details of each classification will be discussed in the next section. 


\subsection{Data}

In understanding the different categories of credit rationing, I use the A2F dataset which contains adequate information about Indonesian households' financial behaviour. The A2F survey was conducted by the World Bank in 2008, covering 3,360 households from ten provinces (see World Bank, 2009). This nationwide survey carefully selected households in order to ensure representativeness by using multistage random sampling based on province (first level), district (second level) and village (third level). The final sample comprised of 1920 households from Java (the main island in Indonesia) and 1,440 from outside Java.

Using DEM method as proposed by Boucher et al. (2009), I classify households according to their status towards the credit market as described in Figure 1. The classification between constrained and unconstrained households is based on the credit supply and households' demand for credit. Using DEM approach, the classification can be brought into operational concept in household surveys such as the A2F survey. The difference between Boucher et al. (2009) and this study is that the A2F survey questions tried to capture and identify credit rationing based on the actual experience of the household, while Boucher et al. (2009) use respondents' opinions or perceptions about the possibility of getting credit from a bank.

\subsection{Credit constraint classifications}

Suppose $D_{h}^{N}$ denotes household $h$ 's notional demand for credit and $D_{h}^{E}$ denotes household $h$ 's effective demand for credit. Notional demand for credits implies households' demand for credit when first-best world exists or when credit markets are perfect assuming the absence of well-functioning insurance markets.

Effective demand for credit implies demand for credit contracts available in a world with asymmetric information. $S_{h}$ denote the maximum amount of credit which can be supplied by a lender to household $h$.

A household can be considered unconstrained if he is not affected by asymmetric information. Unconstrained also implies price-rationed, meaning that credit limit levied by lenders will not bind for these households where:

$$
D_{h}^{E}=D_{h}^{N} \leq S_{h}
$$

Unconstrained households can be also divided into two groups: borrowers who have positive effective demands and non-borrowers who have zero effective demand for credits.

The constrained households can be divided into two types: demand-side and supply-side constrained. A household can be considered as supply-side constrained or quantity rationed when a credit limit is binding as follows:

$$
D_{h}^{N} \geq D_{h}^{E}>S_{h}
$$

Equation (2) implies that household $h$ 's notional demand for credit is equal or greater than effective demand for credits, but the credit supply is lower than the effective demand for credit. One important characteristic from supply-side constrained is that the constraint comes from the credit supply in terms of credit limit. The households' 
effective demand may be lower than notional demand due to asymmetric information. If a household secures less credit than the desired credit then equation (2) will hold.

Figure 1 Borrowing classification (see online version for colours)

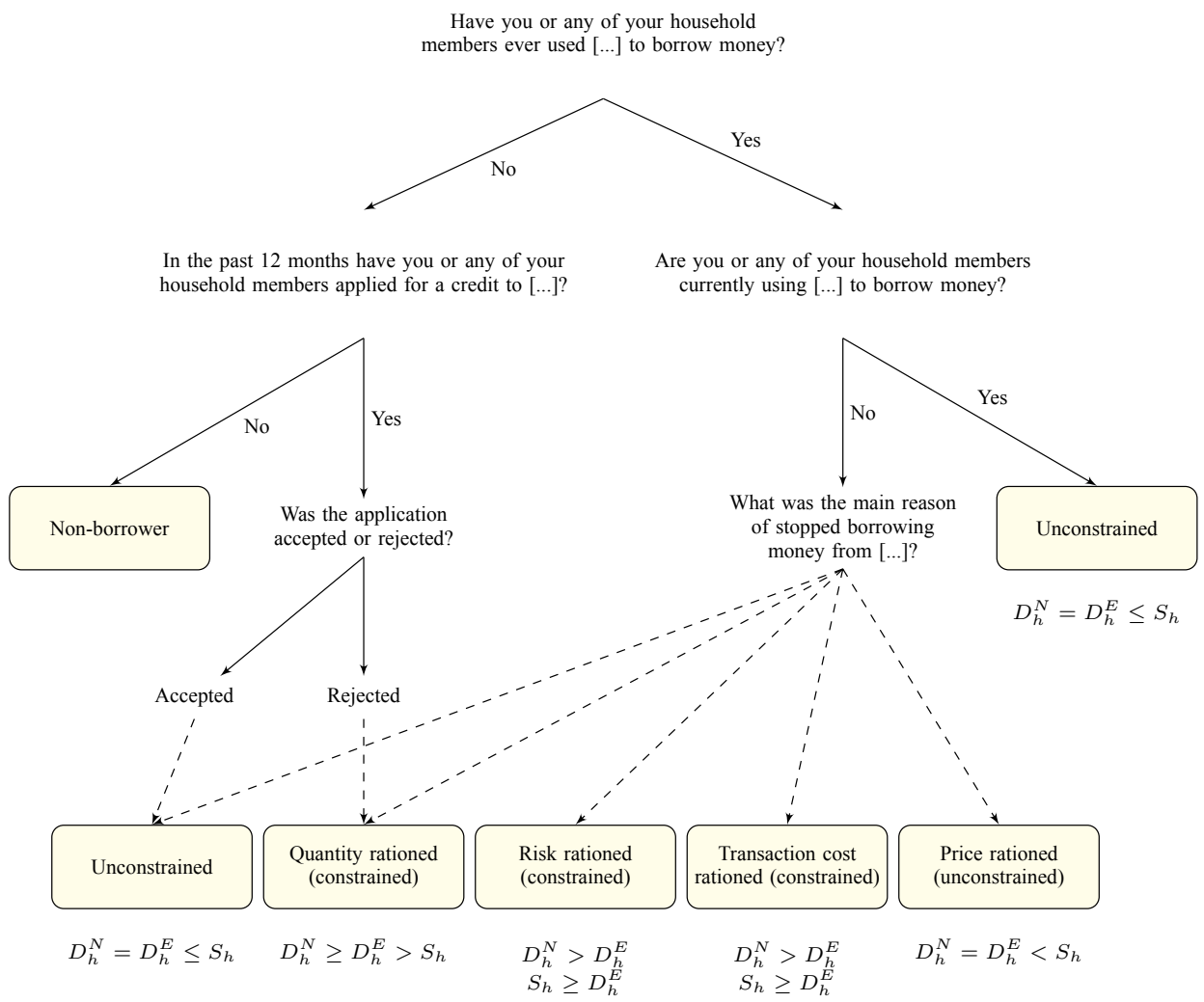

Notes: The questions are taken from A2F survey module. [...] denotes the type of financial institutions or services which the respondents were able to choose from available options. Only respondents who use formal financial institutions are included in the analysis. This includes formal financial institutions such as government-owned bank, private bank; and micro finance such as cooperatives, Islamic saving and loan cooperative, formal saving by non-governmental organisation. $D_{h}^{E}$ denotes household's effective demand for credit, $D_{h}^{N}$ denotes household's notional demand for credit, and $S_{h}$ denotes credit supply.

Source: Author's summary from the A2F dataset

In identifying quantity-constrained households in the A2F survey, households classified in this category are mainly rejected applicants. Those who were rejected in their application have positive effective demand for credit; however, they face a zero credit limit from lenders. Boucher et al. (2009) identify two other groups that fall into this category: unsatisfied borrowers and 'certainly rejected' applicants. Unsatisfied borrowers currently have credits but are asking for more. In other words, the credit amount for this group is lower than their effective demand for credit. The applicants who are 'certain' of loan rejection are those who have positive effective demand and do not apply for a 
credit. This is caused by past credit history or perceptions of credit limit rules. However, questions with regard to these two types of borrowers are not included in A2F survey.

Households who are demand-side constrained can be expressed as follows:

$$
\begin{aligned}
& D_{h}^{N}>D_{h}^{E} \\
& S_{h} \geq D_{h}^{E}
\end{aligned}
$$

where the credit limit is not binding. Equation (3) implies effective demand is lower than notional demand for credits that exists because of transaction costs or risk sharing rules of first-best contract. Equation (4) implies that credit supply limits the effective demand for credits.

Table 1 Reasons for lack of effective demand for credits

\begin{tabular}{lc}
\hline Classification & Reasons of stop borrowing \\
\hline Unconstrained & Do not need to borrow \\
\hline Price rationed & Prefer to save \\
& Interest rate too high \\
\hline Risk rationed & Worry about the repayment \\
& Not enough collateral \\
& Decided to use another source of credits \\
& Unfavourable credit term \\
& Unfavourable repayment schedule \\
& Do not have job or business \\
& Do not have enough money \\
\hline Transaction-cost rationed & The bank officers were unfriendly or unhelpful \\
& Inconvenient location \\
Quantity rationed & Institution not existed anymore \\
\hline
\end{tabular}

Notes: The questions are taken from A2F survey module where the respondents are asked what was the main reason they stopped borrowing money from a particular formal financial institution. The respondents should choose one of these options or state a reason of stopped their borrowings (Question E1.3). The elicited responses are then classified into five borrowing classifications.

Source: Author's summary from A2F dataset

In this particular case, the low level of effective demand is due to either risk or transaction costs. To distinguish between risk and transaction-cost rationed, it is necessary to classify households' responses as described in Table 1.

The A2F also provided an alternative answer for respondents who wish to provide a specific reason apart from available options by writing down their own reason on the 'other' option. The reasons can be classified into one classification: risk, transaction cost or price reason. Furthermore, it is important to note that the respondents already had loans from the financial institutions, but then they decided to stop borrowing due to a particular reason. 


\subsection{Empirical strategy}

Identifying credit constraints using the DEM approach is essentially trying to gather information by capturing all relevant variables from borrowers' perceptions. Boucher et al. (2009) address some issues in using the DEM approach. The first issue is the respondents' perception of financial service provider definition. The sources of credit may imply different credit rules that may also influence the decision to apply for credit. This may also help to test sector-specific hypothesis of credit sources. The A2F questionnaire provides options relating to various types of financial institutions so that it would be easy for respondents to give accurate responses.

The second issue is about household versus individual constraint. The A2F survey explicitly describes that the constraints are addressed at household level, which means that this is consistent with a 'unitary' household definition. This implies that the household head should be able to identify the effective and notional demand for credit for the entire household. The next issue is using respondents' perceptions of lender supply rules. The questions should be properly designed so that they are understood by respondents.

Since various household characteristics are used to observe credit rationing, the analysis will be conducted within a multivariate environment in particular multinomial logit model. Suppose $Y_{h}$ is a categorical variable which represents observable credit rationing of household $h$ and takes value $0,1, . ., I . Y_{h i}^{*}$ is defined as the unobserved 'propensity' of household $h$ fall into credit rationing category $i$ :

$$
Y_{h i}^{*}=\beta^{\prime} X_{h}+\varepsilon_{h i}
$$

where $\beta$ denotes a vector of parameters with the $i^{\text {th }}$ category, $X_{h}$ denotes a vector of household characteristics, $\varepsilon_{h i}$ denotes unobservable component of the household $h$ 's propensity to be in the category $i$, and credit rationing regimes are indexed by $i$.

The $\varepsilon_{h i}$ are independent and identically distributed with Weibull distribution assuming $I+1$. The probability of household $h$ in category $i$ is

$$
\operatorname{Pr}\left(Y_{h}=i\right)=\operatorname{Pr}\left(Y_{h i}^{*}>Y_{h j}^{*}\right) \quad \forall i \neq j .
$$

The objective here is to assess the correlation between the observed rationing category and other factors that may influence credit demand such as risk preferences and financial literacy. Another relevant variable to be considered is the applicant's earnings or income. This gives insight into the borrowing capacity and ability to repay the credits. The annual income is the total of all household members' income comprising earnings or salary, grants or transfers, rent fee, and interest income. Household assets can also be used as the collateral required by the banks. Other variables are discussed as follows.

\subsubsection{Asset index}

Since the nominal values of asset data are not provided in the A2F survey, I use asset index as proposed by Filmer and Pritchett (2001) as a proxy for collateral. They tested the index using data from India, Indonesia, Pakistan, and Nepal. They also show that this index have reasonable correlation between expenditures and asset variables from the same households. Furthermore, they argue that the asset index can be used a proxy for economic status for a household. 
The questions in A2F concerning asset variables are given in two parts or subsections. The first part comprises questions the structure of the building such as main material used for the most part of the house, roof, floor, and electricity. This part also asks about house ownership, rent payment (if the house is rent), and credit instalment (if the house is purchased using credit).

The second part of this survey section comprises of assets owned by households. The respondents are asked whether they have a specific asset and then they are asked the quantity of asset owned by them, except for land, which is in terms of square metre. The type of asset comprises 22 components, which are used to construct the asset index. The respondents can specify one asset that is not given in the list. However, this is not included in the asset index construction because it may not be the same asset type for all households.

Using principal component analysis, the index is constructed from various asset ownership indicators that are aggregated into one variable. The index assumes that the maximum variances and covariances in the asset variables can be used to explain household wealth in the long run. After the principal components are derived and the 'scoring factors' are recovered, the index score for each household is calculated.

\subsubsection{Risk aversion}

In order to capture household's risk preference by the elicitation approach, the A2F provides a set of questions that relate to household perception about risk (A2F Questionnaire Section L). The A2F provides a set of questions that captures household perception of risk. The respondents are asked to play a 'game' in which they have a chance to earn a small amount of money. The question is simple, if a respondent is willing to play the game, he or she will draw a marble from a bag of white and black marbles. If he draws a white ball, then he will get Rp 5,000 and 0 for a black marble. If the respondent is not willing to play, then he or she will certainly get $\mathrm{Rp} 2,000$. The other option is to refuse to play. The risk aversion can be defined as follows

$$
U(a) \leq \frac{1}{2} U(b)+\frac{1}{2} U(d)
$$

where $a, b$ and $d$ are the value different expected payoff which are $\mathrm{Rp} 2,000, \mathrm{Rp} 5,000$ and 0 respectively. The utility function is assumed to be:

$$
U(c)=\frac{c^{1-\gamma}}{1-\gamma}
$$

where $\gamma$ is the coefficient of constant relative risk aversion. Equation (7) implies that one will choose uncertain payoff if the expected utility of this payoff is equal or higher to the expected utility of certain payoff. In order to get values for the coefficient of constant relative risk aversion, plug equation (8) into equation (7), then solve to get $\gamma$. The range of $\gamma$ is between 0.244 and 2.385. Respondents with higher $\gamma$ are more risk averse. To understand respondents' attitudes towards credit or financial services, a financial literacy variable is used. The A2F gives five questions about loan mechanisms (A2F Questionnaire Section K). For example, the question is about interest rate calculation, comparing two different credit schemes, and diversification in farming. The literacy score range is between zero and one where one is the highest score. Furthermore, the 
level of education may also affect household decision making in applying for a credit. Therefore, the highest attainment level of education of the household head is also taken into account.

\subsubsection{Financial literacy}

Financial literacy can be defined as a quantitative measure of households' financial decision making (see Attanasio and Weber, 2010). The questions concerning financial literacy in the A2F follow Lusardi and Mitchell (2014, 2008).

The questions are designed to capture households' understanding about four basic financial skills and knowledge. These are

1 numeracy and the ability to calculate interest rate compounding

2 numeracy and the ability to understand the concept of time value of money

3 understanding of the concept of inflation

4 understanding the principle of risk diversification.

The correct answer for each question has value of one and otherwise is zero. All answers are divided by four to get overall score. Therefore, the maximum score is one and the minimum score is zero. The questions are designed to be simple, relevant to daily financial decision, concise, and able to distinguish financial knowledge across households.

\subsection{Welfare loss estimations using matching models}

In order to measure welfare loss due to credit constraints, I use matching models in particular average treatment models to evaluate the effects of inadequate credit access for households. The matching models overcome selection bias if OLS methods are used to estimate such data.

Average treatment effect (ATE) models are mainly use to evaluate economic policy such as job training (Heckman et al., 1997) and credit policy (Rui and Xi, 2010). Rosenbaum and Rubin (1983) show that matching between treated and control units based on propensity scores is sufficient if conditional independence assumption holds. This model also assumes counterfactual settings which refer to the fact that one individual household has only one outcome. In this study, the treated units are households who are likely to be constrained, and the control units are borrowers who are not constrained by credit access or price-constrained households.

Following Rosenbaum and Rubin (1983), the propensity score is defined as the conditional probability of receiving a treatment:

$$
p(X)=\operatorname{Pr}(W=1 \mid X)=E(W \mid X)
$$

where $W \in\{0,1\}$ indicates the exposure to the treatment and $X$ is the vector of household characteristics. 
If the propensity score for a population of households $p\left(X_{h}\right)$ is known, the average treatment effect on the treated (ATT), in this case to the constrained households, is estimated by:

$$
\begin{aligned}
\tau & =E\left\{Y_{1 h}-Y_{0 h} \mid W_{h}=1\right\} \\
& =E\left[E\left\{Y_{1 h}-Y_{0 h} \mid W_{h}=1\right\}\right] \\
& =E\left[E\left\{Y_{1 h} \mid W_{h}=1, p\left(X_{h}\right)\right\}-E\left\{Y_{0 h}\left|W_{h}=0, p\left(X_{h}\right)\right| W_{h}=1\right\}\right]
\end{aligned}
$$

where $Y_{1 h}$ denotes potential outcome with treatment, and $Y_{0 h}$ denotes potential outcome without treatment.

Since the data is not from experimental design, propensity score matching employed in this study is based on the selection of observables. The idea here is to compare the outcome variables of households who are likely to be constrained with those who are not constrained.

There are four methods of matching the units or these households using propensity scores: nearest neighbour, stratification, radius and kernel. Nearest-neighbour method is a matching of treated units or the constrained households to the control units or unconstrained households with the closest propensity scores. This is usually applied with replacement.

Let $C$ be the set of constrained households as the treated units and $U$ is the set of unconstrained households as the control units. $Y_{h}^{C}$ denotes the observed outcome of constrained households and $Y_{i}^{U}$ denotes the observed outcome of unconstrained households. The nearest neighbour is written as follows:

$$
U(h)=\min _{i}\left\|p_{h}-p_{i}\right\|
$$

where $U(h)$ is the set of unconstrained household characteristics, $p_{h}$ and $p_{i}$ is the estimated value of propensity score of household $h$ and household $i$ respectively.

Stratification can be done by dividing the range of propensity score variations in intervals. Within these intervals, treated and control units will have average propensity scores which can be expressed by

$$
\tau_{q}^{S}=\frac{\sum_{t \in H(q)} Y_{h}^{C}}{N_{q}^{C}}-\frac{\sum_{t \in H(q)} Y_{i}^{U}}{N_{q}^{U}} .
$$

However, some matches may be considered as poor when the nearest neighbour has an extremely different score. This issue can be overcome by implementing the other two matching methods. First by radius matching, constrained households as the treated units are matched only by control units this falls into a predefined neighbourhood of the propensity scores of constrained households. The neighbourhood dimension in this particular case by radius is set in a very small value which may lead to exclusion for some treated units which do not have controls. This can be written as

$$
U(h)=\left\{p_{i} \mid\left\|p_{h}-p_{i}\right\|<r\right\} .
$$

For nearest neighbour matching in equation (11) and radius matching in equation (13), the estimators can be written as

$$
\tau=\frac{1}{N^{C}} \sum_{c \in C} Y_{c}^{C}-\frac{1}{N^{C}} \sum_{j \in U} w_{j} Y_{j}^{U}
$$


where $N^{C}$ is the number of units of constrained households in treated groups and $w_{j}$ are the weights defined by $w_{j}=\sum_{h} w_{h j}$.

By using kernel-matching method, all constrained households as treated units are matched with a weighted average of unconstrained households as control units. The weights are set to be inversely proportional between the propensity scores of constrained and unconstrained households.

$$
\tau^{K}=\frac{1}{N^{C}} \sum_{h \in T}\left\{Y_{h}^{C}-\frac{\sum_{i \in U} Y_{i}^{U} R\left(\frac{p_{h}-p_{i}}{b_{n}}\right)}{\sum_{k \in U} R\left(\frac{p_{h}-p_{i}}{b_{n}}\right)}\right\}
$$

where $R(\cdot)$ is a kernel function and $b_{n}$ is a bandwidth parameter. The welfare loss can be estimated using the average treatment effects (ATT) between constrained and unconstrained households.

To get empirical results, I employ Stata's pscore package for the estimation of various matching models. This package estimates propensity scores and ATT for each matching technique (see Becker and Ichino, 2002).

\section{Analysis and discussions}

\subsection{Data description}

In the A2F survey, financial institutions can be divided into formal and informal institutions. Formal institutions are divided into three types: banks, micro finance institutions and pawnshops. Banks in the A2F include government banks, private banks including Islamic banks, and people credit banks (BPR). Microfinance institutions include credit associations or cooperatives, Islamic saving and loan cooperatives (BMT), and formal saving institution by non-government organisations (NGOs). Employers, daily banks, community welfare schemes, neighbourhood community, and family or friends are considered as informal sources of credit. This study focuses on formal financial institutions since these institutions ideally should cover many households as possible. Respondents who are in the process of getting loans would not be considered in the samples.

Based on the $\mathrm{A} 2 \mathrm{~F}$ dataset, more than $17 \%$ of the total households do not have any access to formal or informal financial institution in terms of credit and $45 \%$ of households only use informal sources of credits. If the numbers of households who use both are added, then $73 \%$ of households utilise informal financial services to get a credit. For non-Java provinces, there are around $5 \%$ of total respondents in each province who are borrowers. From 3,360 households surveyed, only $8 \%$ of total households secured credit from formal financial institutions only, $44 \%$ of total households had credit from informal sources only and $26 \%$ of total households borrowed from both sources. These facts suggest that banks and other formal institutions are still unable to cover the majority of households despite high growth of financial service expansion after year 2000.

Only households with complete information are used in the analysis. From 3,360 households in A2F, the final samples used are 1,775 households which comprise of 1,050 rural households and 725 urban households. Therefore, the sample rate used in the analysis is $53 \%$ of the A2F households. 
Table 2 Credit constraints based on household location

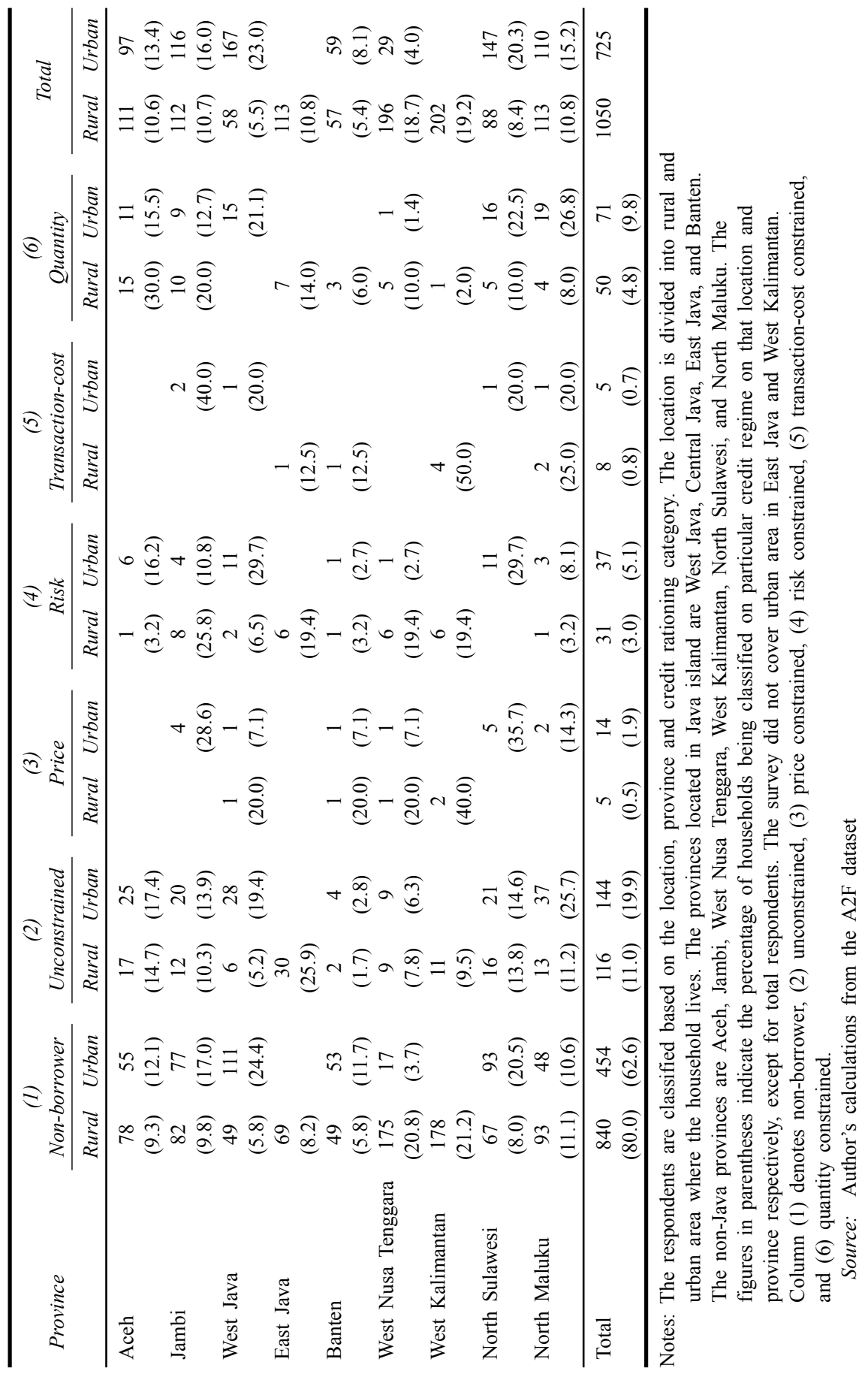


Table 3 Means of key variables for each ration category

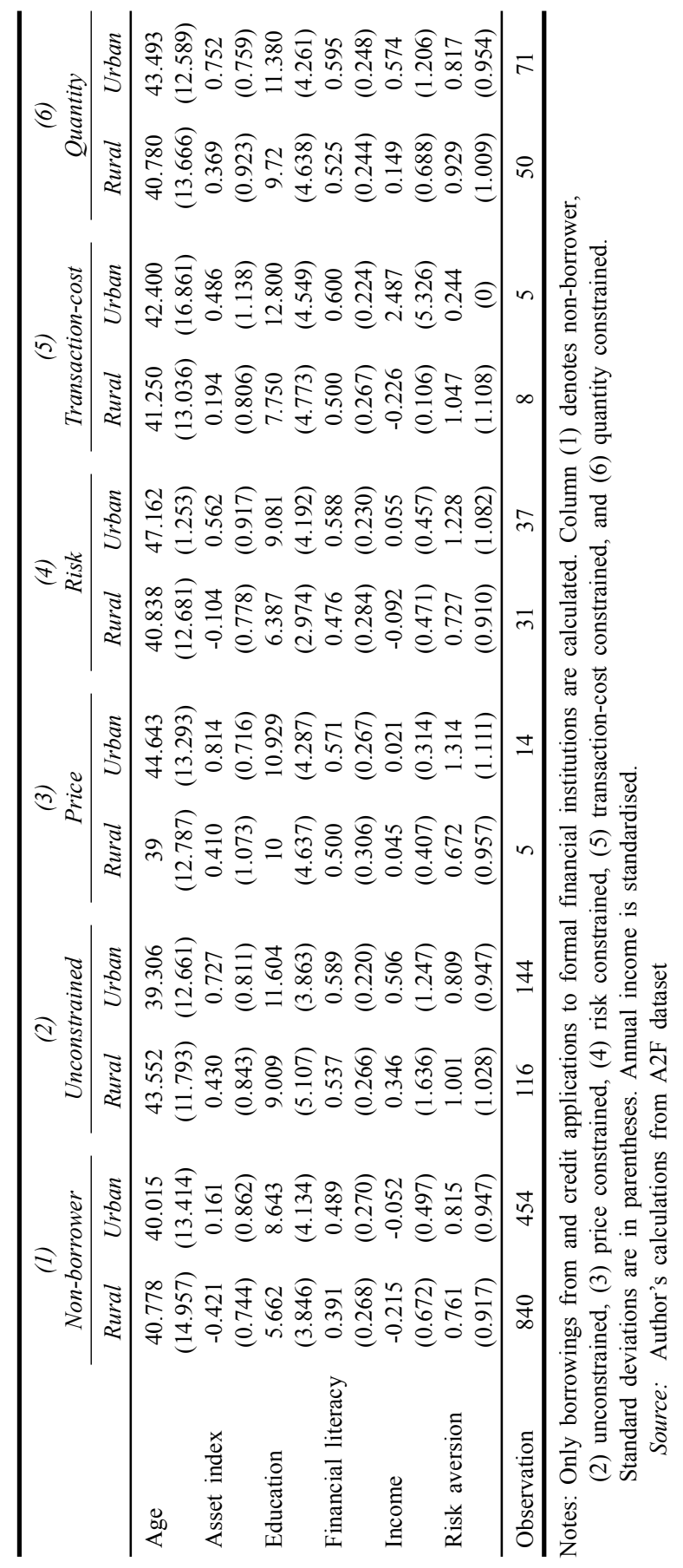


Table 2 provides household samples based on their location and credit classification. The majority of urban households do not borrow from formal financial institutions. In urban area, households also have similar characteristics and have higher proportion than urban household counterpart. In many provinces, the proportion of households who do not borrow is on average around ten percent except for rural households in West Nusa Tenggara and West Kalimantan and for urban households in Jambi, West Java and North Sulawesi, which are around $20 \%$.

In terms of unconstrained regime, urban households comprise of around twenty percent while rural households comprise of eleven percent. This shows that access to formal financial institutions may likely to occur in urban area. However, the lowest proportion of unconstrained households can be found in Banten province. This is quite interesting because Banten is a Java province, which was a part of West Java province until 2000. As a newly formed province, it seems that formal financial institutions have not well developed in Banten for both rural and urban area since it was separated from West Java province.

Credit constraints due to price-related reason seems occur in a small number of respondents. For non-price reason, risk-related reasons take place more than transaction-cost constraints. Demand-side credit constraints, which are due to price and risk rationing, are likely to incur in urban than rural area. The number of households who are constrained by supply-side or quantity rationing is also higher in urban area than rural area.

In summary, the number of urban households who can access formal financial institutions is higher than rural households. The number of unconstrained households also follows similar pattern where urban households are higher than rural households. However, credit rationing is also likely to incur more for urban households than rural households.

Table 3 describes relevant household characteristics which are related to financial market activity. Households use some of their assets as collateral in order to secure credits from financial institutions.

The negative value of the average asset index for non-borrowers implies that these households have a low value of assets. The high value of asset index can be found for unconstrained and price rationed households, indicating their ability to fulfil credit requirements from the lenders.

The annual income is standardised from total household income for the past 12 months. Similar to asset index, non-borrowers have a relatively low level of income compared to average households. The quantity-constrained households have a relatively high level of average annual income compared to other credit constraint categories.

For risk preference, households who had their credit application rejected are less averse than others. This confirms that the lenders are reluctant to approve the application because quantity-rationed households exhibit risk-taking behaviour. Households who fall in the transaction-cost rationed category have a relatively high level of risk aversion as well as negative annual income. This may also explain why these households have more aversion given low levels of income.

As expected, households who are non-borrowers tend to have lower financial literacy scores than other households who are borrowers. This implies that financial literacy seems play a vital role in household decision making to apply for a loan. In other words, non-borrowers seem reluctant to apply for a credit loan due to their understanding toward financial products and knowledge. Households who are quantity rationed seem 
to have a better knowledge of financial information. This may imply they have better understanding toward financial information which motivates them to approach formal financial institutions in order to get a loan. The rest of households in other categories have relatively similar average financial literacy scores between $57 \%$ and $60 \%$.

In summary, $\mathrm{A} 2 \mathrm{~F}$ households have relatively different characteristics when they are classified based on a credit constraint regime. The results provide initial conditions that could confirm the source of constraints still exists in credit markets.

\subsection{The impact of different credit constraint regimes}

The use of DEM in defining the type of credit constraints faced by households requires accurate questionnaire design to distinguish each credit constraint regime. Such classifications can be done as the required information given in the A2F questionnaire enables us to do so. After the households are classified into the appropriate regime, the multinomial logit along with the marginal effects can be estimated for each classification simultaneously. The purpose of this analysis is to evaluate the impact of the probability of being observed in each rationing regime where the independent variables are evaluated at median values. The marginal impact of regressors for each rationing is given in Table 4.

Table 4 Marginal impact of regressors on the probability of each credit constraint regime and non-borrower

\begin{tabular}{lcccccc}
\hline & $(1)$ & $(2)$ & $(3)$ & $(4)$ & $(5)$ & $(6)$ \\
& Non-borrower & Unconstrained & Price & Risk & Transaction-cost & Quantity \\
\hline Age & $-0.004^{* * *}$ & $0.001^{* *}$ & 0.000 & $0.001^{*}$ & 0.000 & $0.001^{* *}$ \\
& $(0.001)$ & $(0.000)$ & $(0.000)$ & $(0.000)$ & $(0.000)$ & $(0.000)$ \\
Asset & $-0.077^{* * *}$ & $0.039^{* * *}$ & 0.007 & -0.013 & 0.001 & $0.017^{*}$ \\
& $(0.016)$ & $(0.010)$ & $(0.005)$ & $(0.009)$ & $(0.004)$ & $(0.007)$ \\
Education & $-0.015^{* * *}$ & $0.008^{* * *}$ & 0.001 & -0.000 & 0.001 & $0.005^{* * *}$ \\
& $(0.003)$ & $(0.002)$ & $(0.001)$ & $(0.002)$ & $(0.001)$ & $(0.001)$ \\
Financial literacy & $-0.141^{* * *}$ & $0.058^{*}$ & 0.003 & 0.047 & 0.003 & 0.030 \\
& $(0.040)$ & $(0.024)$ & $(0.007)$ & $(0.026)$ & $(0.011)$ & $(0.017)$ \\
Annual income & $-0.041^{*}$ & $0.030^{* *}$ & -0.007 & 0.001 & 0.004 & $0.012^{*}$ \\
& $(0.019)$ & $(0.009)$ & $(0.006)$ & $(0.011)$ & $(0.003)$ & $(0.005)$ \\
Risk aversion & -0.015 & 0.004 & 0.003 & 0.007 & -0.000 & 0.001 \\
& $(0.009)$ & $(0.005)$ & $(0.002)$ & $(0.005)$ & $(0.003)$ & $(0.004)$ \\
\hline
\end{tabular}

Notes: Column (1) denotes non-borrower, (2) unconstrained, (3) price constrained,

(4) risk constrained, (5) transaction-cost constrained, and (6) quantity constrained. To estimate the marginal effects, the regressors are set to equal to the sample median. The income variables are standardised. The subdistrict (kecamatan) dummy is used as control variables. Standard errors are reported in parentheses. Coefficients significant at the $10 \%$ level are denoted by $*$, at the $5 \%$ level by **, and at the $1 \%$ level by $* * *$.

Source: Author's summary from A2F dataset

Starting with quantity-rationed regime in Table 4 column (6), the probability of quantity-rationed household increases as the asset index increases. This type of rationing 
would be related to some credit rules that is usually evaluated by lenders. The credit rules are usually related collateral or some assets that could be pledge in order to get credit loans. The possible explanation for this is because potential borrowers are required to pledge some of their worthy assets in order to apply for a credit that may not fulfil the requirement needed to get a credit loan. The household income may also play role in this context. For quantity-constrained households, the probability of being classified in this category increases as household income increases. Although the households have certain level of income, this is not adequate to secure a loan from formal financial institutions. If we compare the marginal effect of annual income between quantity-constrained households and unconstrained households, the effect for the latter is lower than the former. From these results, it can be inferred that the credit rule imposed by formal financial institutions can be assessed through the marginal effects.

The other variables that have significant effects for quantity-rationed households are the age of respondents and their education level. The effect of age for quantity-constrained households is similar to risk-constrained households and unconstrained borrowers. For the level of education, the possibility of being quantity rationed increases as the level of education is higher. Financial literacy and risk preference of households seem do not have any effects in determining probability of being classified in this regime. Households in the quantity-rationed regime are said to have a binding supply-side constraint.

As mentioned before, non-price rationing can be divided into risk and transaction-cost rationing. However, for the transaction-cost rationed, nothing can be inferred [see Table 4 column (5)]. This is due to an inadequate number of sample households for this regime. For the risk-rationed household, the age of the respondents is the only variable that has significant and positive effect to the probability of being classified in risk-rationed regime. This effect is similar to the same variable as for quantity-constrained households and unconstrained households. It seems that experience affects the way households interact with formal financial households. As households get older, they accumulate experience in terms of interacting with these institutions.

Following Boucher et al. (2009), unconstrained households can be divided into price rationing households and unconstrained borrowers. Price rationed households here are those who stop borrowing loans from formal financial institutions due to price-related reasons. For price-constrained households, the case is the same as transaction-cost constrained households where the number of sample households may not be adequate to estimate the marginal effects.

For borrowers, the effect on the probability of being unconstrained is increasing as regressors increased with the exception of risk aversion. It can be interpreted that these households have adequate collateral capacity in terms of asset and income would lead to higher probability of being unconstrained borrowers. The possibility of being accepted is because the lenders are able to observe their financial capacity based on the households' asset and income. Again, if we compare the marginal effects of these two variables, the unconstrained households have higher effects than any other households in other regimes. It can be inferred that their asset and income are above certain level, which is imposed by formal financial institutions.

Unconstrained households are also financially literate which implies that they have adequate knowledge in accessing and using loans from lenders. This can be shown given the fact that the effect of financial literacy increases as the probability of being 
observed in this regime also increases. In other words, those who are well informed about financial knowledge are likely to apply successfully for credit from financial markets. The effect of age for unconstrained borrowers is also increasing significantly. However, it has similar effect with risk-constrained and quantity-constrained households. The level of last education obtained by the head of the household also has positive effect toward the probability of being classified as unconstrained households. Again, the marginal effect of education level for unconstrained households is the highest among credit constraint classification. This suggests that people who obtained higher level of education may be able to secure loans from formal financial institutions.

As anticipated, the overall impact of explanatory variables to the probability of non-borrowers has significant and negative marginal effects, except for risk aversion. The non-borrowers are defined as households who do not apply for a loan to formal financial institutions. The impacts of asset and income indicate low capability in providing collateral to gain credit. This may suggest that non-borrower households have less confidence whenever they have to deal with formal financial institutions especially in terms of applying and securing a loan from these institutions.

The marginal effect of age for non-borrower households is significant and negative. This may imply that younger households tend to be classified as non-borrower. The similar interpretation can be also used to explain the level of education for non-borrower households. Since the marginal effect of education is significantly negative, it can be said that those who have lower level of education may not be able to or have less access to formal financial institutions.

Moreover, the negative impact of financial literacy score indicates that they do not have adequate knowledge of credit with its related information. One interesting fact is that the marginal effect of financial literacy for non-borrower households is higher than any effects given by the rest of the variables. This means that financial literacy is very critical component in explaining low level of the accessibility of formal financial institutions in Indonesia. The low level of financial literacy also implies that if borrowers know that the loan is too risky for them, and then they may reluctant to continue using credit and stop borrowing. Another possible explanation is that since they are well informed about the credit terms, they are able to measure their ability to face future consequences. Therefore, they feel it would be difficult to fulfil loan requirements.

To conclude, the key point here is each credit constraint regime can be identified and distinguished by using multinomial logit method. Although there are inadequate samples for price and transaction-cost constraint observation, this method is still reliable to distinguish the effect of different credit constraint regime. The results show that there are different characteristics between households given their credit constraint classification. This excludes the age where the effects are quite similar for unconstrained borrowers, quantity-rationed and risk-rationed households.

\subsection{Welfare loss estimation}

The most important question with regard to credit constraint classification is about the impact of inadequate access to financial markets. Therefore, the welfare loss can be used to answer this issue. The method used here is an ad-hoc approach using matching models.

After classifying credit regime in the previous section, the constrained households are then matched against unconstrained households who are borrowers. Table 5 
provides estimation results, the impact of credit constraints on per capita income with different treated units: price, risk, transaction-cost and quantity-rationed households. The unconstrained households are used as control in matching methods. It should be noted that the context of this case is only for formal financial institutions based on the A2F data.

Table 5 Estimation results of matching models for each regime

\begin{tabular}{lcccc}
\hline $\begin{array}{l}\text { Matching } \\
\text { methods }\end{array}$ & $\begin{array}{c}\text { Price } \\
\text { constrained }\end{array}$ & $\begin{array}{c}\text { Risk } \\
\text { constrained }\end{array}$ & $\begin{array}{c}\text { Transaction-cost } \\
\text { constrained }\end{array}$ & $\begin{array}{c}\text { Quantity } \\
\text { constrained }\end{array}$ \\
\hline Stratification & -23.6 & $-16.0^{* * *}$ & 29.3 & -4.23 \\
Nearest neighbour & $(10.0)$ & $(6.18)$ & $(49.3)$ & $(8.74)$ \\
& -48.1 & -19.2 & 50.6 & -8.92 \\
Radius & $(4.45)$ & $(6.44)$ & $(36.9)$ & $(6.40))$ \\
& -23.6 & $-19.2^{* * *}$ & 29.2 & -6.67 \\
Kernel & $(5.57)$ & $(7.98)$ & $(50.5)$ & $(7.31)$ \\
& -24.0 & $-16.9^{* * *}$ & 29.4 & -6.51 \\
& $(9.24)$ & $(5.03)$ & $(3.64)$ & $(8.04)$ \\
\hline
\end{tabular}

Notes: The coefficients are in millions Indonesian rupiah. The treated observations are households being constrained in a particular credit rationing regime and the control observations are unconstrained borrowers. Standard errors are reported in parentheses. Coefficients significant at the $10 \%$ level are denoted by $*$, at the $5 \%$ level by $* *$, and at the $1 \%$ level by ***.

Source: Author's summary from A2F dataset

The credit constraints have negative impacts on annual income across different regimes with the transaction-cost constrained group as an exception. However, these methods are only able to significantly estimate for risk-constrained households. Using a different approach of matching models, it can be shown that the welfare loss range due to risk constraints is between Rp 16 millions to Rp 19 millions which are statistically significant except for the nearest neighbour matching method. The nearest-neighbour method seems to generate lower figures since it takes the nearest unit between propensity scores of constrained and unconstrained households as treated and control units. The impact of risk rationing for households is between these figures, which can be interpreted as + a decrease in annual income.

The coefficients for the price constrained indicate welfare loss, which are higher than risk rationing. However, since the coefficients are not statistically significant, the loss may not be there. This is understandable: they refuse to continue using loans because they are not affected by asymmetric problems.

None of the coefficients for the transaction-cost constrained regime gives statistical meaning. However, since the sign of the coefficients are different from other credit constraint regimes, it is possible that administrative factors in formal financial institutions do not significantly affect household welfare. In other words, households are no or less affected by transaction-cost factors such as inconvenient location and unfriendly bank officers. Households may still able to cope with their financial circumstances even tough they have stopped borrowing from formal financial institutions. 
For the quantity-constrained households, although the coefficients are not significant, the losses are lower than other credit constraint regime. The possibility is that these households face supply side constraints, meaning that they may have other sources of financing that enable them to have lower impacts than others.

\section{Concluding remarks}

It should be noted that the purpose of DEM is to identify circumstances in multiple type of credit constraints, not to explain how to alleviate the problems. The results provide evidence of credit constraint in Indonesian households represented in the A2F survey using the DEM approach. This approach is able to distinguish the difference between each regime.

Using multinominal logit approach, I find household characteristics except risk aversion play important role in distinguishing unconstrained and constrained households. In particular, financial literacy is the most important one than other characteristics in understanding unconstrained borrowers. Households who are credit constrained mostly due to supply-side factors. This implies a challenge to formal financial institutions to evaluate their credit policy towards households. However, the results for price and transaction-cost constraints are not sufficient due to the small number of observations.

This study is only able to confirm the welfare loss estimation for risk constrained. Those who are unable to access credit markets due risk-related factors suffer loss in terms of income smoothing between Rp 16 millions and 19 millions. From the welfare loss estimations, it can be inferred that the credit constraints for Indonesian households are more likely due to demand-side constraints in particular risk rationing. This fact can be seen as an opportunity to tap into constrained households by giving adequate information and offering credit terms which are appropriate for them.

In this study, the limitation comes from the survey data where it does not provide adequate information on those households who are constrained by price reason and transaction-cost factors. Another limitation is that the approach only allows for one category for each household. The argument is that a household may be classified into various categories which is likely to change the welfare loss estimation. Furthermore, a natural expansion of this study using the same dataset is investigating the spill-over effects from formal to informal financial institutions. The reasons why households use informal financial institutions may also explain inaccessible formal financial services to many Indonesian households.

\section{Acknowledgements}

This paper is an extension of Chapter 5 of my doctoral thesis. I thank the participants of the 2014 Asian Finance Association Annual Conference for their helpful comments. I gratefully acknowledge scholarship support from the Ministry of National Education, the Republic of Indonesia. Usual disclaimer applies. 


\section{References}

Attanasio, O.P. and Weber, G. (2010) 'Consumption and saving: models of intertemporal allocation and their implications for public policy', Journal of Economic Literature, Vol. 48, No. 3 pp.693-751.

Becker, S. and Ichino, A. (2002) 'Estimation of average treatment effects based on propensity scores', Stata Journal, Vol. 2, No. 4, pp.358-377.

Binswanger, H.P. and Sillers, D.A. (1983) 'Risk aversion and credit constraints in farmers' decision-making: a reinterpretation', The Journal of Development Studies, Vol. 20, No. 1, pp.5-21.

Boucher, S.R., Guirkinger, C. and Trivelli, C. (2009) 'Direct elicitation of credit constraints: conceptual and practical issues with an application to Peruvian agriculture', Economic Development \& Cultural Change, Vol. 57, No. 4, pp.609-640.

Deaton, A. (1991) 'Saving and liquidity constraints', Econometrica, Vol. 59, No. 5, pp.1221-1248.

Deaton, A. (1992) 'Household saving in LDCs: credit markets, insurance and welfare', Scandinavian Journal of Economics, Vol. 94, No. 2, pp.253-273.

Eswaran, M. and Kotwal, A. (1990) 'Implications of credit constraints for risk behaviour in less developed economies', Oxford Economic Papers, Vol. 42, No. 2, pp.473-482.

Fernando, N.A. (2007) Low-Income Households' Access to Financial Services: International Experience, Measures for Improvement, and the Future, EARD Special Studies [online] http://www.adb.org/Documents/Books/Low-Income-Households/low-income-household.pdf (accessed 31 December 2013).

Filmer, D. and Pritchett, L.H. (2001) 'Estimating wealth effects without expenditure data-or tears: an application to educational enrollments in states of India', Demography, Vol. 38, No. 1, pp.115-132.

Ghosh, P., Mookherjee, D. and Ray, D. (2001) 'Credit rationing in developing countries: an overview of the theory', in Mookherjee, D. and Ray, D. (Eds.): Readings in the Theory of Economic Development, pp.283-301, Blackwell Publishers Ltd, Oxford.

Grant, C. (2007) 'Estimating credit constraints among US households', Oxford Economic Papers, Vol. 59, No. 4, pp.583-605.

Heckman, J.J., Ichimura, H. and Todd, P.E. (1997) 'Matching as an econometric evaluation estimator: evidence from evaluating a job training programme', The Review of Economic Studies, Vol. 64, No. 4, pp.605-654.

Jappelli, T. (1990) 'Who is credit constrained in the U.S. economy?', The Quarterly Journal of Economics, Vol. 105, No. 1, pp.219-234.

Lusardi, A. and Mitchell, O.S. (2008) 'Planning and financial literacy: how do women fare?', American Economic Review, Vol. 98, No. 2, pp.413-417.

Lusardi, A. and Mitchell, O.S. (2014) 'The economic importance of financial literacy: theory and evidence', Journal of Economic Literature, Vol. 52, No. 1, pp.5-44.

Petrick, M. (2005) 'Empirical measurement of credit rationing in agriculture: a methodological survey', Agricultural Economics, Vol. 33, No. 2, pp.191-203.

Rosenbaum, P.R. and Rubin, D.B. (1983) 'The central role of the propensity score in observational studies for causal effects', Biometrika, Vol. 70, No. 1, pp.41-55.

Rui, L. and Xi, Z. (2010) 'Econometric analysis of credit constraints of Chinese rural households and welfare loss', Applied Economics, Vol. 42, No. 13, pp.1615-1625. 
Schneider, D. (1987) 'Agency costs and transaction costs: flops in the principal-agent-theory of financial markets', in Bamberg, G. and Spremann, K. (Eds.): Agency Theory, Information, and Incentives, pp.481-494, Springer Berlin Heidelberg, Berlin.

World Bank (2009) Improving Access to Financial Services in Indonesia, Working Paper No. 52032 [online] http://go.worldbank.org/2IW7WYK0D2 (accessed 31 December 2010). 